\title{
Environmental aspects of heat recovery systems of boiler plants
}

\author{
Nataliia Fialko ${ }^{1, *}$, Raisa Navrodska ${ }^{1}$, Malgorzata Ulewicz², Georgii Gnedash ${ }^{1}$, \\ Sergii Alioshko ${ }^{1}$, and Svitlana Shevcuk ${ }^{1}$ \\ ${ }^{1}$ The Department of Thermophysics of Energy Efficient Heat Technologies, Institute of Engineering \\ Thermophysics of National Academy of Sciences of Ukraine, Kyiv, Ukraine \\ ${ }^{2}$ Faculty of Civil Engineering, Czestochowa University of Technology, Czestochowa, Poland
}

\begin{abstract}
The results of studies on improving the environmental characteristics of boiler plants of municipal heat-power engineering in the application of technologies for the deep recovery of heat from exhaust-gases of gas-fired boilers are presented. The data on the reduction of environment by reducing the amount and temperature of harmful emissions resulting from fuel combustion are given. The data are given for boiler plants equipped with complex heat-recovery systems characterized by cooling the exhaust-gases below the dew point of the water vapor contained in them. It is shown that the decrease in emissions is due to a decrease in fuel consumption in boilers due to the beneficial use of the heat of exhaust-gases in these systems and the dissolution of nitrogen and carbon oxides in the condensate, formed in the heat-recovery equipments. The analysis of improving the environmental safety of boiler plants when used in heat-recovery technologies of corrosion protection systems for chimneys has been performed. Anticorrosion protection is provided by preventing condensate formation in the exhaust-gas ducts of boiler plants when using technologies for the deep recovery of exhaust-gas heat. To prevent condensate formation, the method of pre-drying cooled exhaust-gases in a heat exchanger-preheater installed after heat-recovery equipment is used. It is also shown that the use of complex heat-recovery systems provides in the boiler plant additional water in the form of condensate formed during condensation of moisture from exhaust-gases. Receipt of this condensate is another ecological effect of heat-recovery, which allows reducing the consumption of natural water resources for supply municipal heat networks.
\end{abstract}

\section{Introduction}

At present, the problems of rational use of fuel and energy resources and improvement of the ecological situation are priorities in the world energy practice. The relevance of scientific tasks in these areas is increasing due to the constant increase in the cost of fuel and the increasing requirements to reduce environmental pollution. The main ways to solve

\footnotetext{
* Corresponding author: nmfialko@ukr.net
} 
these important problems in the production of heat energy in the municipal sector is to improve the environmental performance of gas-fired boilers and increase the efficiency of their use of fuel in the application of technologies the deep recovery-heat of the exhaust-gases [1-6] or other companion waste heat [7]. It should be noted that the use of these technologies is characterized by obtaining an environmental effect in several directions.

\section{Prerequisites and means for solving the problem}

These technologies provide a reduction in fuel consumption in the boiler due to a decrease in the exhaust-gas temperature through the beneficial use of their heat. At the same time, the coefficient the use heat of fuel (CUHF) of boiler or its efficiency significantly increases. In this case, the environmental performance of the boiler is also improved by reducing temperature pollution of the environment and reducing harmful emissions resulting from fuel combustion.

The reduction in fuel consumption and, consequently, the reduction of harmful emissions of $\Delta C$ into the environment are determined by the depth of cooling of the exhaust-gases in a boiler plant containing a boiler equipped with a heat-recovery system. In certain modes of the boiler in this system, the exhaust-gas temperature decreases below the dew point of the water vapor contained in them. There comes the so-called condensation mode of operation of heat-recovery equipment, when in addition to the so-called clear heat of exhaust-gases, the latent heat of condensation of this vapor is used.

In fig. 1 shows data on the magnitude of the reduction in emissions of $\Delta C$ due to an increase in boiler efficiency and a decrease in fuel consumption depending on the exhaustgas temperature at the outlet of the boiler plant.

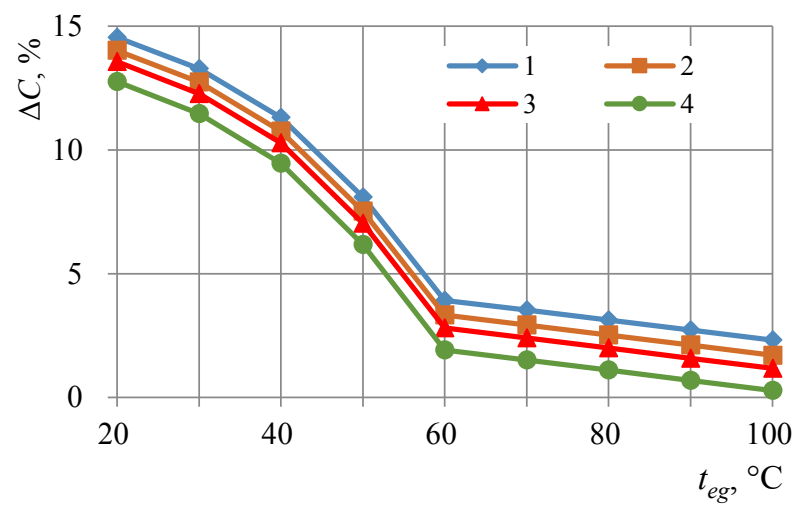

Fig. 1. The dependence of the relative reduction of harmful emissions $\Delta C$ of the boiler plant from the temperature of exhaust-gases at the outlet $t_{\text {eg }}$ for various heat loads of the boiler: $1-Q_{b} / Q_{\text {nom }}=100 \% ; 2-70 \% ; 3-50 \% ; 4-30 \%$.

The data are given for a gas-fired water-heating boiler, type KSVA-2.0G with a nominal heating capacity of $2 \mathrm{MW}$ when calculated from the highest calorific value of fuel. The nominal temperature $t_{e g}$ of the boiler exhaust-gases and the coefficient of air excess $\alpha$ in them are $170^{\circ} \mathrm{C}$ and 1.1 , respectively. With this value of $\alpha$, the dew point $t_{d p}$ of water vapour contained in the exhaust-gases is close to $58^{\circ} \mathrm{C}$.

As can be seen from the presented results, in all modes of operation of the boiler, there is a tendency of a significant increase in the value of $\Delta C$ when cooling the exhaust-gases below the dew point $t_{d p}$, that is, when operating in the condensation mode. So, with 
a nominal load of the boiler and a decrease in the exhaust-gas temperature from $170^{\circ} \mathrm{C}$ to the temperature at which water vapor starts to condense on the heat exchange surfaces (i.e., when heat-recovery is carried out in the dry mode), the maximum efficiency of the boiler and the corresponding reduction in harmful emissions is $4.3 \%$. Under the conditions of operation of the boiler plant with this load in the condensation mode, a reduction in harmful emissions of $\Delta C$ may be as the exhaust-gas temperature drops to $50^{\circ} \mathrm{C}-8.5 \%$; up to $40^{\circ} \mathrm{C}-11.8 \%$ and up to $30^{\circ} \mathrm{C}-13.7 \%$. In the event of a decrease in the boiler load below the nominal, the relative amount of harmful emissions of $\Delta C$ decreases slightly due to a decrease in fuel consumption in the boiler.

In traditional heat-recovery systems used in municipal heat and power engineering mainly for heating boilers and intended only for heating the return heat-network water entering the boiler, this condensation mode is usually implemented only in the autumn-spring period of the heating season with relatively minor loads of the boiler. In order to ensure this mode throughout the entire heating period, it is necessary to use the recovery heat also for heating heat-transfer agents colder than return heat-network water. Such heat-transfer agents can be cold water of the chemical water-purification system of the boiler plant, technological water, combustion air, etc.

\section{Solution of the examined problem}

The complex heat-recovery system using the received heat to heat the return heat-network water and the combustion air is shown in fig. 2 .

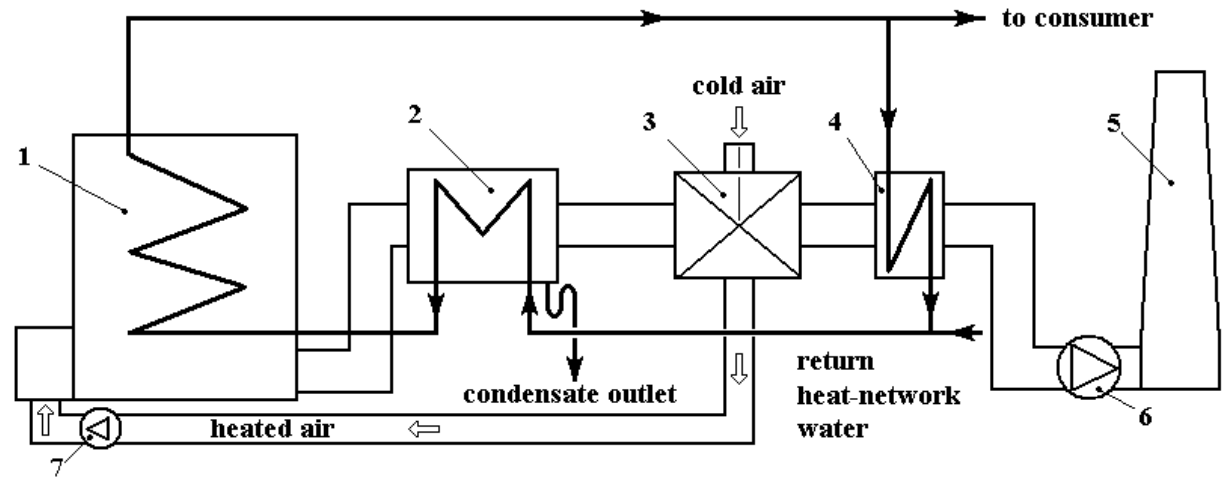

Fig. 2. Basic scheme the heat-recovery installation with the complex use water-heating and air-heating heat-recovery exchangers: 1 - boiler; 2 - heater of return heat-network water; 3 - air-heater; 4 - gas-heater; 5 - chimney; 6 - exhauster; 7 - fan.

In this system, the exhaust-gases of the boiler are cooled first in the water-exchanger, heating the return heat-network water before it is supplied to the boiler, and then cooled in the air heat exchanger, which heats the combustion air. Both heat-recovery exchangers can operate in condensation mode. This mode is carried out in the cold season mainly in the air-heating heat-recovery exchanger due to low air temperature, and in the autumn-spring heating season in the water-exchanger when the heated water temperature going down below the dew point $t_{d p}$ of exhaust-gases.

When calculating the thermal and increasing the efficiency of the boiler, the characteristics of the above-mentioned KSVA-2.0G boiler, calculated from the highest calorific value of fuel, were used. The air-heating heat exchanger of the system was made up of packages of stainless steel plates, and the water-heating one was made of a bundle of transverse-finned bimetallic pipes (carbon steel base, aluminium fins). 


\section{Results and discussion}

In fig. 3 shows the results of computational studies of the levels of reduction of harmful emissions $\Delta C$ by increasing the boiler efficiency when using the heat-recovery system during the heating period. Wherein, the heat load of the boiler changed depending on the environment air temperature with the adopted temperature difference in the heat-network of $70-115^{\circ} \mathrm{C}$.

The results show that the use of air and water heat-recovery exchangers provides a level of reduction of harmful emissions during the heating period in the ranges of $2.1-4.0 \%$ and $2.8-5.9 \%$, respectively. At the same time, the reduction of emissions of the entire system is $6.0-7.5 \%$, which is a significantly higher level compared to the use of single heat exchangers.

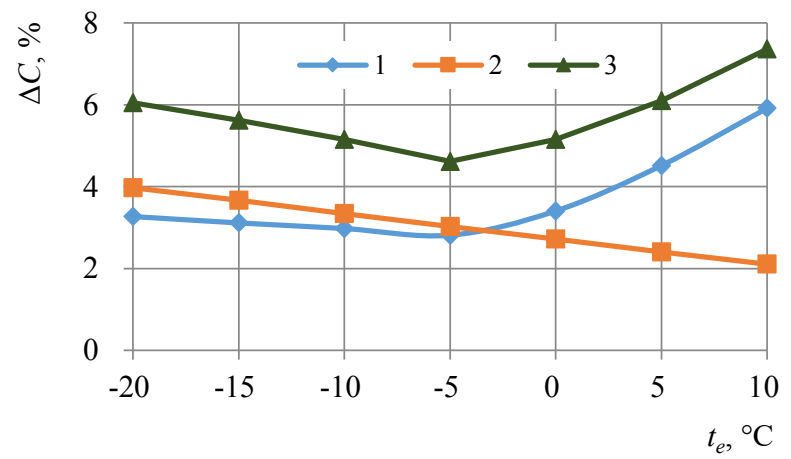

Fig. 3. Dependence on the outdoor temperature the relative reduction of harmful emissions $\Delta C$ boilers with a complex heat-recovery system through the use of a heat exchanger for heating return heat-network water (1), combustion air (2) and when they are used together (3).

It should be noted that the realized of the condensation mode in the complex heatrecovery systems of boiler plants in addition to reducing harmful emissions by increasing the efficiency boiler is characterized by an additional effect. This effect is to reduce harmful emissions due to partial dissolution of the nitrogen and carbon oxides contained in the exhaust-gases in the condensate obtained during the deep cooling of gases. This effect is much smaller in magnitude compared with the effect associated with reduced fuel consumption. Its value depends on the composition of the fuel and the environmental performance of burners, and for modern boilers it is estimated to be less than $1 \%$.

The next, very important environmental aspect of the use of modern complex heatrecovery systems is to ensure the environmental safety of municipal facilities through the use of anti-corrosion protection of boiler chimneys in these systems. Chimneys, as is well known, must fulfil strict environmental requirements regarding the maintenance of regulatory dispersion of pollutants contained in the flue gases of boiler plants, and high demands are placed on them for their reliability.

The use of heat-recovery technologies without protection systems for gas exhaust-ducts leads to corrosion destruction of the exhaust-ducts and chimneys [8-10]. This is due to the deep cooling of exhaust-gases in heat-recovery systems. In this case, further cooling of the exhaust-gases and condensation of the water vapor remaining in them occurs in the gasexhaust ducts of the boiler plant, including the chimney, and a problem called "chimneys are crying" occurs. The condensate formed is acidic; its $\mathrm{pH}$ in gaseous fuel is 5-6. This circumstance enhances the corrosion destruction of exhaust-ducts. At the same time, the most vulnerable section of the gas exhaust-duct is the mouth of the flue, the last section of this duct along the exhaust-gas path. 
It should be noted that even when heat-recovery installations are operating in the dry mode (without reducing the exhaust-gas temperature below the dew point), there is an increased condensate formation in the chimney due to the subsequent cooling of these gases in the exhaust-gas duct. When using heat-recovery technologies with deep cooling of exhaust-gases, a significant amount of moisture from them is condensed in the heatrecovery equipment. This reduces the dew point of the exhaust-gases, which significantly improves the conditions for ensuring the prevention of condensate formation in the exhaust ducts.

To prevent the formation of condensate in the exhaust-gas ducts of boiler plants in modern heat-recovery systems, thermal methods are used to prevent condensate formation $[4,9,10]$. The proposed heat-recovery system (see fig. 2) provides for thermal protection of the exhaust ducts from condensation, which is provided by applying the thermal method of drying exhaust-gases after the heat-recovery system in the heat exchanger gas-heater.

The effectiveness of this method essentially depends on the type of chimney used, which determines the insulating properties of its body. In fig. 4 shows data on the heat and humidity characteristics at the mouth of chimneys of various types (brick and metal with thermal insulation) during the heating period when used in systems for heat recovery of gas-heaters.

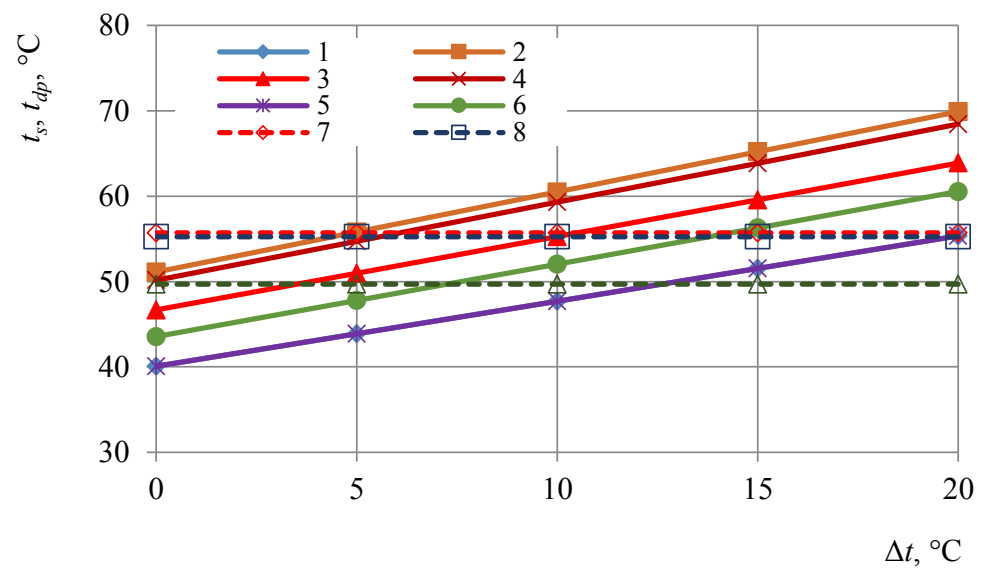

Fig. 4. The dependence of the temperature of the inner surface $t_{s}$ at the mouth of chimneys (1-6) and the dew point $t_{d p}$ (7-9) from the levels of heating $\Delta \mathrm{t}$ of exhaust-gases at different environment temperatures $t_{e}: 1,3,5$ - brick; 2, 4, 6 - metal with heat insulation $(\lambda=0.065 \mathrm{~W} /(\mathrm{m} \cdot \mathrm{K}), \delta=50 \mathrm{~mm})$ chimneys: $1,2,7-t_{e}=-20^{\circ} \mathrm{C} ; 3,4,8-t_{e}=-5^{\circ} \mathrm{C} ; 5,6,9-t_{e}=10^{\circ} \mathrm{C}$.

The data obtained indicate that for the absence of condensation at the mouth of the chimney in these modes of operation of the boilers it is necessary to heat the flue gases to values $\Delta t=10^{\circ} \mathrm{C}$ and $17^{\circ} \mathrm{C}$ for brick and metal pipes, respectively. That is, for the environmental safety of boiler plants of municipal heat-power engineering facilities, it is advisable to apply heat-recovery technologies with anti-corrosion protection of the gas exhaust ducts.

The environmental aspects of heat-recovery systems also include the possibility of condensate in them. In fig. 5 shows the dependencies regarding the amount of condensate heat generated in the complex heat-recovery system also for the gas-fired boiler type KSVa-2.0 with a nominal heating capacity of $2 \mathrm{MW}$. Data is based on $1 \mathrm{MW}$ of installed boiler capacity.

As can be seen from the presented results, during the heating period, the output of condensate in the complex heat-recovery system is from 21 to $40 \mathrm{~kg} / \mathrm{h}$ per $1 \mathrm{MW}$. When 
operating a boiler plant with an installed capacity of $30 \mathrm{MW}$, for example, up to 29 tons of condensate can be formed per day.

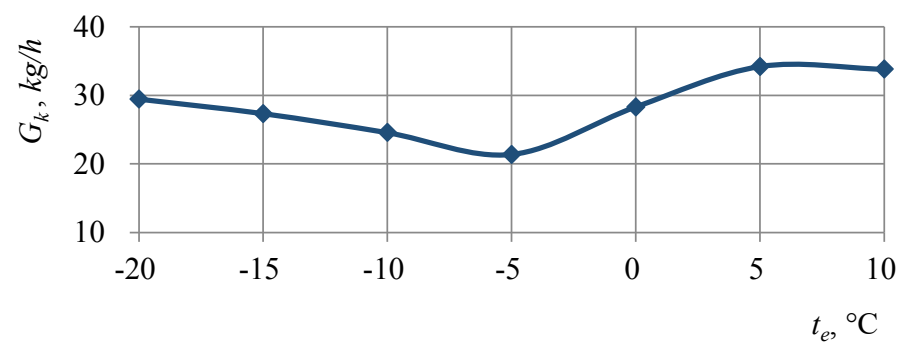

Fig. 5. The formation of condensate at $1 \mathrm{MW}$ of installed power of the boiler depending on the environment temperature $t_{e}$ during the heating period when using a complex heat-recovery system.

The resulting condensate can be used, in particular, in chemical water-purification systems of boiler plants to supply heating-networks. This circumstance ensures a reduction in the consumption of natural water resources in the heat supply systems of municipal heat and power engineering.

\section{Conclusions}

In conclusion, it should be noted that the conducted studies have shown significant environmental efficiency of modern heat-recovery technologies for boiler plants. So the application of these technologies in the municipal heat-power engineering provides:

- a reduction of up to $7.5 \%$ of the harmful emissions generated by the combustion of natural gas in boilers, by reducing its consumption with the beneficial use of the heat of exhaust-gases;

- a reduction of up to $1 \%$ of the emissions of oxides of nitrogen and carbon contained in the flue gases by partially dissolving them in the condensate obtained during the deep cooling of these gases;

- ecological safety of communal heat and power engineering objects when using heat-protection technologies of heat-recovery systems of exhaust-gas ducts against condensate formation;

- saving natural water resources due to the beneficial use of condensate formed in heatrecovery systems.

\section{References}

1. A. V. Efimov, A. L. Goncharenko, A. B. Goncharenko, Bulletin of the National Technical University "KhPI" 13, 987, 73-80 (2013)

2. I. N. Artemov, E. A. Artemova, Most complete utilizing the heat of exhaust gases boilers (Energy efficient and resource-saving technologies and systems, 126-129, 2014)

3. N. M. Fialko, R. A. Navrodskaya, G. A. Presich, M. A. Novakovskiy, Technological systems 77, 4 (2016)

4. N. Fialko, R. Navrodskaya, G. Gnedash, G. A. Presich, A. I. Stepanova, S. I. Shevchuk, International Scientific Journal for Alternative Energy and Ecology 15, 126-129 (2014)

5. A. A. Dolinskiy, N. M. Fialko, R. A. Navrodskaya, G. A. Gnedash, Industrial Heat Engineering 36, 4, 27-35 (2014) 
6. N. M. Fialko, G. A. Presich, G. A., Gnedash, S. I. Shevchuk, I. L. Dashkovska, Industrial Heat Engineering 40, 3, 38-45 (2018)

7. N. M. Fialko, L. B. Zimin, S. V. Dubovskoy, Promyshlennaya teplotekhnika 22, 1, 90-93 (2000)

8. A. A. Kudinov, K. A. Ziganshina, A.V. Fedotenkova, Energetic 8, 60-62 (2014)

9. N. M. Fialko, R. O. Navrodska, S. I. Shevchuk, G. O. Presich, G. O. Gnedash, Scientific Bulletin of UNFU 27, 6, 125-130 (2017)

10. N. M. Fialko, R. A. Navrodskaya, S. I. Shevchuk, G. A. Presich, G. A. Gnedash, O. Glushak, Modern Science: Researches, Ideas, Results, Technologies 2, 15, 13-17 (2014) 